NASA/TM-2005-214025

\title{
Satellite Propellant Pump Research
}

Steven J. Schneider, Joseph P. Veres, Chunill Hah, Anthony L. Nerone,

Cameron C. Cunningham, Thomas G. Kraft, Paul F. Tavernelli, and Bryan Fraser Glenn Research Center, Cleveland, Ohio 
Since its founding, NASA has been dedicated to the advancement of aeronautics and space science. The NASA Scientific and Technical Information (STI) Program Office plays a key part in helping NASA maintain this important role.

The NASA STI Program Office is operated by Langley Research Center, the Lead Center for NASA's scientific and technical information. The NASA STI Program Office provides access to the NASA STI Database, the largest collection of aeronautical and space science STI in the world. The Program Office is also NASA's institutional mechanism for disseminating the results of its research and development activities. These results are published by NASA in the NASA STI Report Series, which includes the following report types:

- $\quad$ TECHNICAL PUBLICATION. Reports of completed research or a major significant phase of research that present the results of NASA programs and include extensive data or theoretical analysis. Includes compilations of significant scientific and technical data and information deemed to be of continuing reference value. NASA's counterpart of peerreviewed formal professional papers but has less stringent limitations on manuscript length and extent of graphic presentations.

- TECHNICAL MEMORANDUM. Scientific and technical findings that are preliminary or of specialized interest, e.g., quick release reports, working papers, and bibliographies that contain minimal annotation. Does not contain extensive analysis.

- CONTRACTOR REPORT. Scientific and technical findings by NASA-sponsored contractors and grantees.
- CONFERENCE PUBLICATION. Collected papers from scientific and technical conferences, symposia, seminars, or other meetings sponsored or cosponsored by NASA.

- SPECIAL PUBLICATION. Scientific, technical, or historical information from NASA programs, projects, and missions, often concerned with subjects having substantial public interest.

- TECHNICAL TRANSLATION. Englishlanguage translations of foreign scientific and technical material pertinent to NASA's mission.

Specialized services that complement the STI Program Office's diverse offerings include creating custom thesauri, building customized databases, organizing and publishing research results ... even providing videos.

For more information about the NASA STI Program Office, see the following:

- Access the NASA STI Program Home Page at http://www.sti.nasa.gov

- E-mail your question via the Internet to help@sti.nasa.gov

- Fax your question to the NASA Access Help Desk at 301-621-0134

- Telephone the NASA Access Help Desk at 301-621-0390

- Write to:

NASA Access Help Desk

NASA Center for AeroSpace Information 7121 Standard Drive

Hanover, MD 21076 
NASA/TM-2005-214025

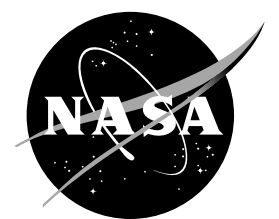

\section{Satellite Propellant Pump Research}

Steven J. Schneider, Joseph P. Veres, Chunill Hah, Anthony L. Nerone, Cameron C. Cunningham, Thomas G. Kraft, Paul F. Tavernelli, and Bryan Fraser Glenn Research Center, Cleveland, Ohio

Prepared for the

41st Joint Propulsion Conference and Exhibit cosponsored by AIAA, ASME, SAE, and ASEE

Tucson, Arizona, July 10-13, 2005

National Aeronautics and

Space Administration

Glenn Research Center 


\section{Acknowledgments}

This work was funded by the Energetics Heritage Project, formerly an element of the Aerospace Technology Enterprise's (Code R) Mission and Science Measurement Technology theme, prior to being transferred to the Exploration Systems Research \& Technology theme in the newly formed Exploration Systems Mission Directorate.

Available from

NASA Center for Aerospace Information 7121 Standard Drive

Hanover, MD 21076
National Technical Information Service 5285 Port Royal Road Springfield, VA 22100

Available electronically at http:/ /gltrs.grc.nasa.gov 


\title{
Satellite Propellant Pump Research
}

\author{
Steven J. Schneider, Joseph P. Veres, Chunill Hah, Anthony L. Nerone \\ Cameron C. Cunningham, Thomas G. Kraft, Paul F. Tavernelli, and Bryan Fraser \\ National Aeronautics and Space Administration \\ Glenn Research Center \\ Cleveland, Ohio 44135
}

NASA Glenn initiated a satellite propellant pump technology demonstration program. The goal was to demonstrate the technologies for a 60 percent efficient pump at $1 \mathrm{gpm}$ flow rate and 500 psia pressure rise. The pump design and analysis used the in-house developed computer codes named PUMPA and HPUMP3D. The requirements lead to a 4-stage impeller type pump design with a tip diameter of 0.54 in. and a rotational speed of 57,000 rpm. Analyses indicated that flow cavitation was not a problem in the design. Since the flow was incompressible, the stages were identical. Only the 2-stage pump was designed, fabricated, assembled, and tested for demonstration. Water was selected as the surrogate fluid for hydrazine in this program. Complete mechanical design including stress and dynamic analyses were conducted. The pump was driven by an electric motor directly coupled to the impellers. Runs up to $57,000 \mathrm{rpm}$ were conducted, where a pressure rise of $200 \mathrm{psia}$ at a flow rate of $0.8 \mathrm{gpm}$ was measured to validate the design effort.

\section{Introduction}

Propulsion systems using pressure-fed, $100 \mathrm{lbf}$ class engines are commonly used for apogee insertion of geostationary satellites and for axial maneuvers of unmanned planetary spacecraft. The performance of these propulsion systems, which use Earth storable (amine) bipropellants, has been maximized by the use of iridium-coated rhenium ( $\mathrm{Ir} / \mathrm{Re}$ ) chamber materials (Ref. 1). The use of the high-temperature, oxidationresistant, Ir/Re chamber reduces the performance degradation due to fuel film cooling. Further increases in $100 \mathrm{lbf}$ class bipropellant engine performance can be obtained by either operation at higher chamber pressures, the use of more energetic propellants, or both. This can be shown by a one-dimensional kinetics nozzle expansion analysis as given in Figure 1. The use of more energetic propellants would require incorporation of at least one cryogen into the propulsion system and would necessitate advancing the technology for long-term cryogenic storage and distribution.

Operation at higher chamber pressures is more of an evolutionary step that can be used with current state-of-art bipropellants (and their system components), and then incorporated into cryogenic propulsion systems when needed. High chamber pressure operation, however, is not practical with pressure-fed systems, since the increase in propellant and pressurant tank masses offset the engine performance gains. Pumped systems are required in order to derive the performance benefit of high pressure operation, but pumps of the required flow rate and pressure rise have not been designed and tested. Existing pump technology is considered to be too unreliable and inefficient by mission planners.

First of all, this paper presents a simplified systems analysis of the benefit of high pressure operation, conducted for both the NEAR and CASSINI missions. This analysis led NASA Glenn to conduct research on storable bipropellant pumps. A goal was set, based on these mission analyses, to deliver the propellants at 550 psia to a $100 \mathrm{lbf}$ class rocket while reducing the operating pressure of the propellant tanks from 300 to 100 psia. The performance goal for this demonstration pump was to increase the pressure from 50 to $550 \mathrm{psia}$ at a flow rate of $1 \mathrm{gpm}$ with 60 percent efficiency. This has the twofold system advantage of both reducing propulsion system dry mass and increasing rocket performance.

Conceptual sizing of the pump to meet these requirements led to a four stage centrifugal design with an impeller tip diameter $0.54 \mathrm{in}$. and a rotational speed of approximately $57,000 \mathrm{rpm}$. Since a high efficiency centrifugal pump of this size has not been demonstrated, a task was defined to demonstrate its feasibility with modern machine tool capabilities. A two-stage design with an overall pressure rise of 


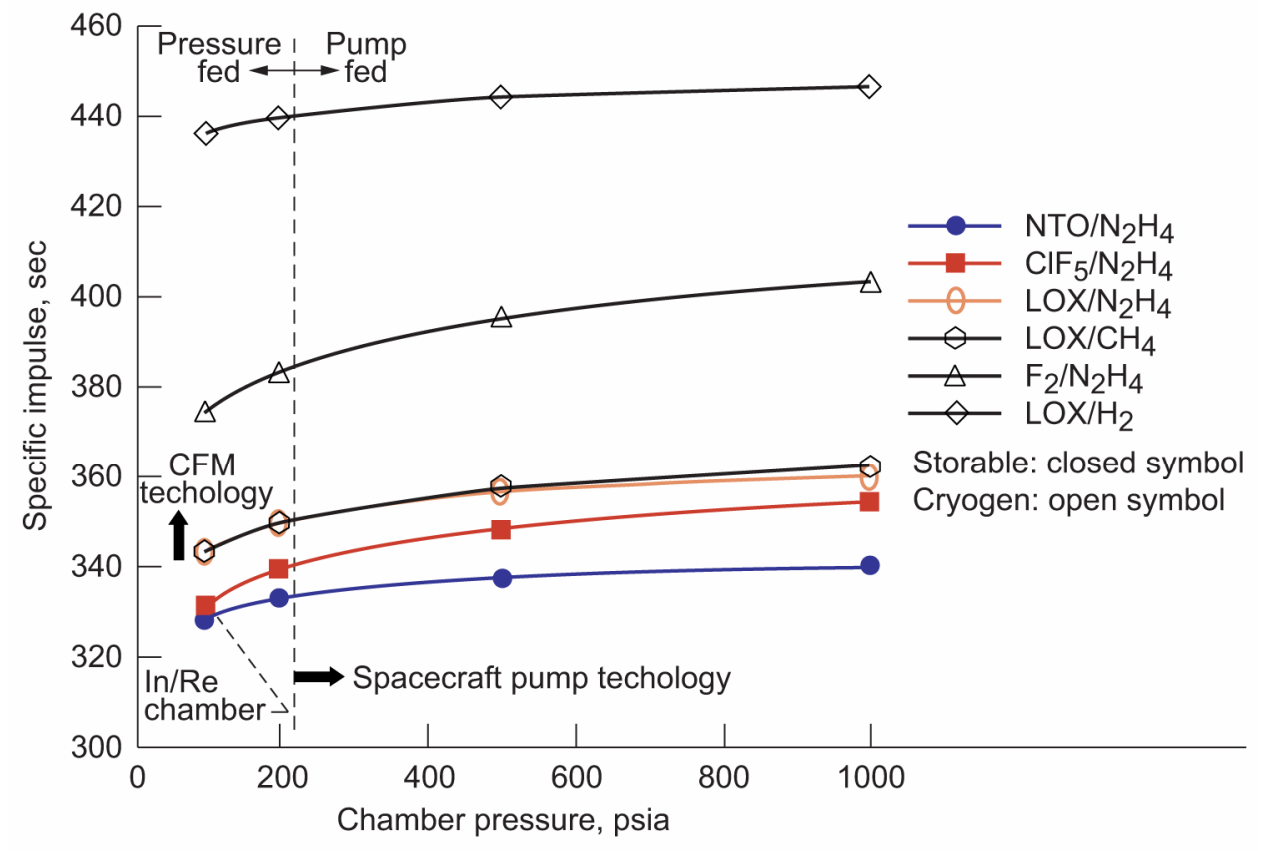

Figure 1.-One Dimensional Kinetics (ODK) performance comparison of various bipropellant combinations.

250 psia was fabricated. The design included crossover de-swirl vanes between the stages and an exit volute. The mechanical layout of the pump was an overhung two stage configuration with interstage seals and with bearings exterior to the pump. Compatibility with hydrazine was a design criterion. Supporting stress and dynamic analyses of the design were given. The anticipated design performance was predicted with a steady, three-dimensional viscous flow calculation. The design was tested on simulated propellant (water) for safety. Pump operation was demonstrated for this report but limited analysis of the pump performance was completed in time for incorporation into this report.

\section{Thermodynamic Analysis of a Pumped System}

A simplified schematic of a turbine driven, pumped satellite propulsion system is shown in Figure 2. The performance of high pressure NTO/hydrazine rockets was already demonstrated by two NASA Glenn contractors (Refs. 2 and 3). Performance at 98 percent of theoretical $\mathrm{C}^{*}$ was demonstrated by one contractor and projected by the other. This leads to a performance estimate of $338 \mathrm{sec}$ Isp for NTO/MMH at a mixture ratio of 2, 400 psia chamber pressure and an area ratio of 200:1. For comparison purposes, it was assumed that with some development a 98 percent theoretical $\mathrm{C}^{*}$ pressure fed engine could be developed with $330 \mathrm{sec}$ Isp at 100 psia chamber pressure and similar design parameters.

Thermodynamic analyses indicated that 500 psia pressure rise could be attained with a pump design requiring about $0.5 \mathrm{~kW}$ of power for each propellant. The required pump power could be delivered by an electric motor as in this experiment or by a gas generator driven turbine. The required electrical power may be available on some communications satellites and on satellites with an electric propulsion system. If a turbine driven system was selected, a gas generator cycle must be designed such that the fuel rich turbine driving gases have sufficient pressure at the turbine exit that they can be injected into the rocket chamber for propulsion purposes. This avoids a significant gas generator performance penalty. 


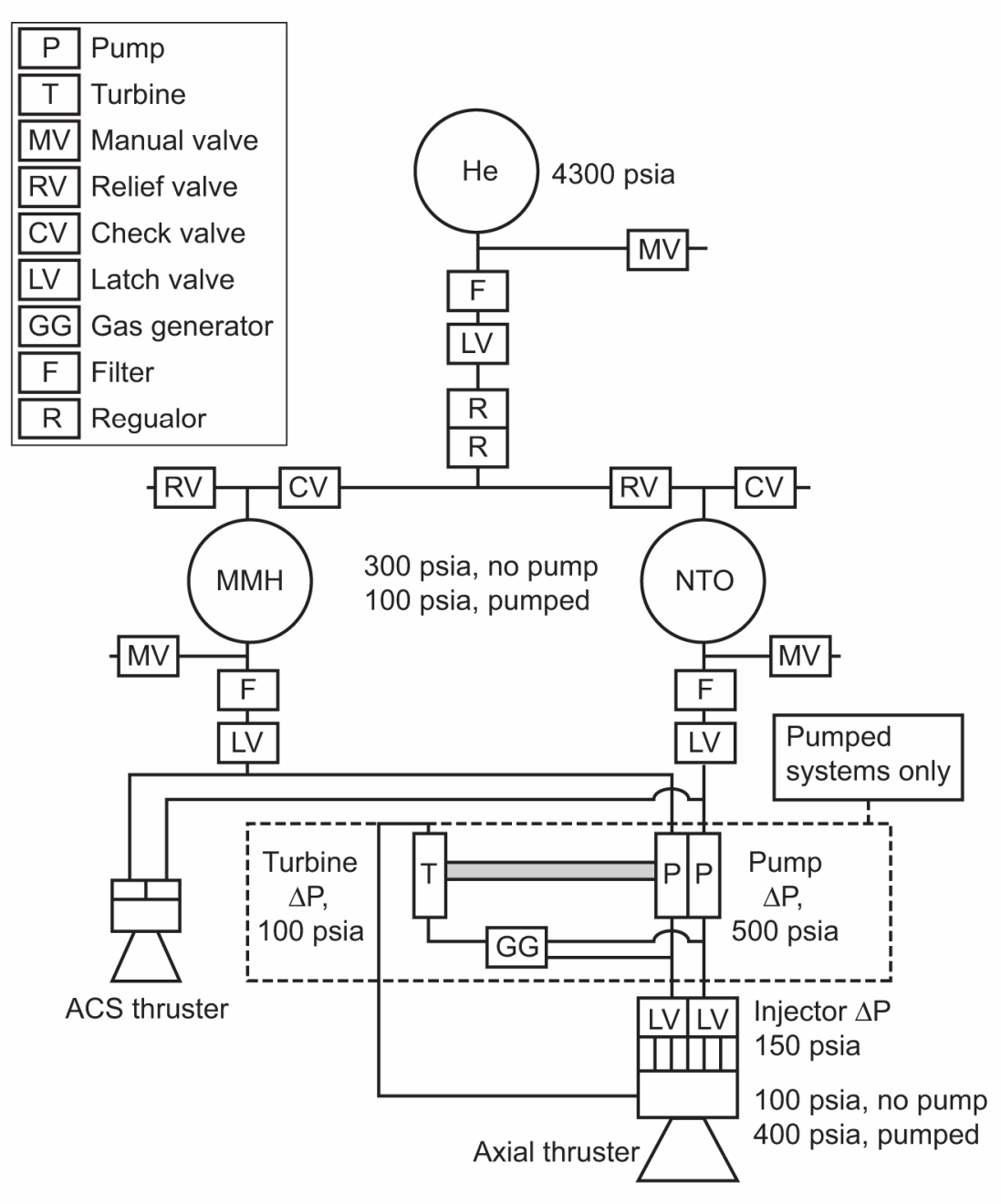

Figure 2.-Schematic of a turbine driven, pumped satellite propulsion system.

Gas generator parameters were selected as used in Reference 4, where it operated at a mixture ratio of 0.18 , producing a combustion gas average temperature of $882^{\circ} \mathrm{C}\left(1620^{\circ} \mathrm{F}\right)$. The turbine speed was matched to that of the pump at $57,000 \mathrm{rpm}$, where 60 percent turbine efficiency is feasible. The $\Delta \mathrm{P}$ across the turbine is 100 psia and $1 \mathrm{~kW}$ of power requires a mass flow of $0.012 \mathrm{~kg} / \mathrm{sec}$, which is about 9 percent of the total mass flow through the rocket $(0.134 \mathrm{~kg} / \mathrm{sec})$.

\section{Pumped Satellite Mission Analysis}

The generic pumped system shown in Figure 2 has three payload benefits: (1) rocket performance increased by about $8 \mathrm{sec}$ by raising the rocket chamber pressure from 100 to $400 \mathrm{psia}$; (2) the weight of the propellant tanks decreased when their operating pressure was reduced from 300 to 100 psia; and (3) the size and therefore the weight of the pressurization system decreased, when the system was pumped. These combined effects more than offset the additional weight of a pump to give the propulsion system additional payload capability. To demonstrate these effects, the NEAR propulsion system described in Reference 5 and the CASSINI propulsion system described in Reference 6 were examined. A propulsion system model developed in Reference 7 incorporated models for both the propellant tanks and the carbon composite overwrapped pressurant tank. The propellant tank dry mass was calculated using two different models. The first, based on geosynchronous satellite data, was first published in Reference 8 
and the second, based on commercially available tanks from Pressure Systems Inc., was published in Reference 9. The dry mass model for the pressurant tank was published in Reference 7 and was shown to model the titanium-lined, carbon composite overwrapped tank from Pressure Systems Inc. that was described in Reference 10.

The NEAR propulsion system parameters are given in Table 1 . The NEAR spacecraft had a beginning of life (B.O.L.) mass of $805 \mathrm{~kg}$. The NEAR axial propulsion system supplied a $\Delta \mathrm{V}=1176 \mathrm{~m} / \mathrm{sec}$. The science payload was $55 \mathrm{~kg}$. The mission used a NTO/MMH propulsion system with significant flight heritage having a performance of $312 \mathrm{sec}$. Using the propulsion system model developed in Reference 7 a comparison of system enhancements was conducted. If the rocket performance was increased to $330 \mathrm{sec}, 11.4 \mathrm{~kg}$ of propellant were saved along with 0.4 to $0.7 \mathrm{~kg}$ of tank mass. Payload could be increased 21 to 22 percent in this case. If a pump were incorporated into the system as shown in Figure 2, the tank pressure could be reduced to 100 psia, while the rocket chamber pressure was raised to 400 psia giving a rocket performance of $338 \mathrm{sec}$. This lead to $16.2 \mathrm{~kg}$ of propellant saved. Reducing the propellant tank pressure to from 300 to 100 psia reduced the tank mass and pressurant system mass 9.4 to $12.0 \mathrm{~kg}$ depending on the tank model used. The pump/motor or pump/gas generator mass was conservatively estimated to be $4.2 \mathrm{~kg}$ based on the hardware developed on this program. The net effect on payload was an increase of 39 to 44 percent as shown in Table 1 and Figure 3.

The CASSINI propulsion system parameters are given in Table 2. CASSINI had a B.O.L. mass of $5609 \mathrm{~kg}$. The CASSINI axial propulsion system supplied a $\Delta \mathrm{V}=2039 \mathrm{~m} / \mathrm{sec}$. The science payload was $684 \mathrm{~kg}$. The flight heritage propulsion system again had $312 \mathrm{sec}$ of performance. If the rocket performance was increased to $330 \mathrm{sec}, 112 \mathrm{~kg}$ of propellant were saved along with 3.5 to $4.7 \mathrm{~kg}$ of tank mass. Payload could be increased 16.9 to 17.1 percent in this case. If a pump were incorporated into the system as shown in Figure 2, $159.1 \mathrm{~kg}$ of propellant could be saved along with 84.7 to $90.3 \mathrm{~kg}$ of propellant tank and pressurant system mass. Again a pump mass of $4.2 \mathrm{~kg}$ was estimated giving a net effect on payload of 35.0 to 35.8 percent as shown in Table 2 and Figure 4.

TABLE 1. PUMP BENEFIT TO NEAR MISSION

\begin{tabular}{|c|c|c|c|c|}
\hline \multirow[b]{2}{*}{ Beginning of life } & \multicolumn{3}{|c|}{ NEAR propulsion system model } & \\
\hline & $\mathrm{kg}$ & 805 & & \\
\hline Payload & $\mathrm{kg}$ & 55 & & \\
\hline Delta-V & $\mathrm{m} / \mathrm{sec}$ & 1176 & & \\
\hline Propellants & & \multicolumn{2}{|c|}{ NTO/MMH } & \\
\hline MR & & 2 & & \\
\hline \multirow[t]{2}{*}{ Pressurant } & $\mathrm{kPa}$ & 29670 & & \\
\hline & & S.O.A. & Advanced & Pumped \\
\hline Isp & $\sec$ & 312 & 330 & 338 \\
\hline Tank pressure & $\mathrm{kPa}$ & 2070 & 2070 & 690 \\
\hline Propellant & $\mathrm{kg}$ & 304.1 & 292.7 & 287.9 \\
\hline Tanks (Ref. 6) & $\mathrm{kg}$ & 15.3 & 15.0 & 8.9 \\
\hline Tanks (Ref. 7) & $\mathrm{kg}$ & 13.2 & 12.6 & 4.2 \\
\hline He tank & $\mathrm{kg}$ & 4.6 & 4.6 & 2.3 \\
\hline $\mathrm{He}$ & $\mathrm{kg}$ & 1 & 0.9 & 0.3 \\
\hline Est. pump mass & $\mathrm{kg}$ & N/A & N/A & 4.2 \\
\hline Propellant saved & $\mathrm{kg}$ & N/A & 11.4 & 16.2 \\
\hline Tank mass saved & $\mathrm{kg}$ & N/A & 0.4 to 0.7 & 9.4 to 12.0 \\
\hline \begin{tabular}{|l} 
Total mass saved \\
\end{tabular} & $\mathrm{kg}$ & N/A & 11.8 to 12.1 & 21.4 to 24.0 \\
\hline$\%$ Payload (55 kg) & & N/A & 21 to 22 percent & 39 to 44 percent \\
\hline
\end{tabular}




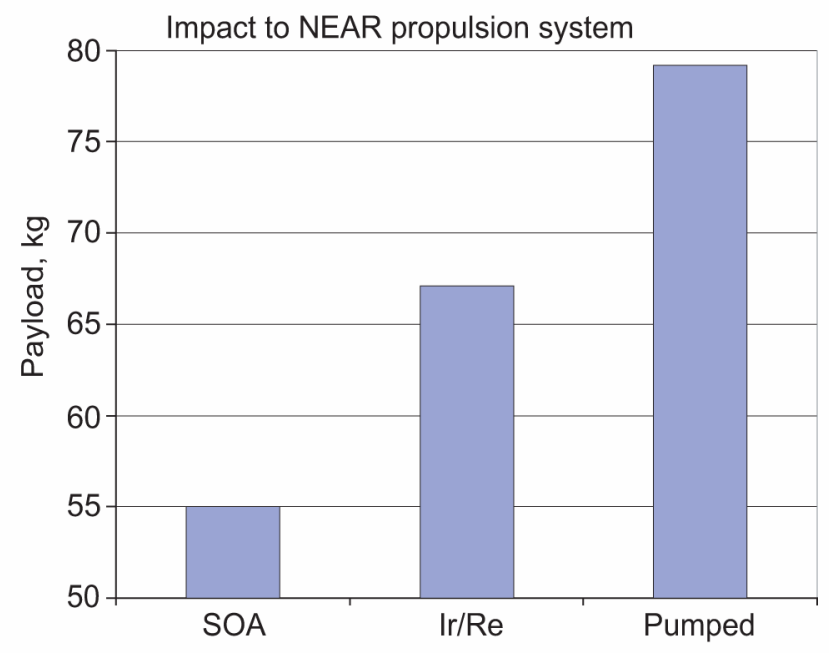

Figure 3.-Payload benefit to NEAR of pumped system.

TABLE 2. PUMP BENEFIT TO CASSINI MISSION

\begin{tabular}{|c|c|c|c|c|}
\hline \multirow[b]{2}{*}{ Beginning of life } & \multicolumn{3}{|c|}{ CASSINI propulsion system model } & \\
\hline & $\mathrm{kg}$ & 5609 & & \\
\hline Payload & $\mathrm{kg}$ & 684 & & \\
\hline Delta-V & $\mathrm{m} / \mathrm{sec}$ & 2039 & & \\
\hline Propellants & & \multicolumn{2}{|c|}{ NTO/MMH } & \\
\hline MR & & 2 & & \\
\hline \multirow[t]{2}{*}{ Pressurant } & $\mathrm{kPa}$ & 29650 & & \\
\hline & & S.O.A. & Advanced & Pumped \\
\hline Isp & $\sec$ & 312 & 330 & 338 \\
\hline Tank pressure & $\mathrm{kPa}$ & 2070 & 2070 & 690 \\
\hline Propellant & $\mathrm{kg}$ & 2865.0 & 2753.0 & 2705.9 \\
\hline Tanks (Ref. 6) & $\mathrm{kg}$ & 89.5 & 86.1 & 29.8 \\
\hline Tanks (Ref. 7) & $\mathrm{kg}$ & 95.8 & 93.6 & 30.5 \\
\hline He tank & $\mathrm{kg}$ & 28.2 & 27.2 & 9.5 \\
\hline $\mathrm{He}$ & $\mathrm{kg}$ & 9.0 & 8.7 & 2.7 \\
\hline Est. pump mass & $\mathrm{kg}$ & N/A & N/A & 4.2 \\
\hline Propellant saved & $\mathrm{kg}$ & $\mathrm{N} / \mathrm{A}$ & 112.0 & 159.1 \\
\hline Tank mass saved & $\mathrm{kg}$ & N/A & 3.5 to 4.7 & 84.7 to 90.3 \\
\hline Total mass saved & $\mathrm{kg}$ & N/A & 115.5 to 116.7 & 239.6 to 245.2 \\
\hline \%Payload (684 kg) & & N/A & 16.9 to 17.1 percent & 35.0 to 35.8 percent \\
\hline
\end{tabular}




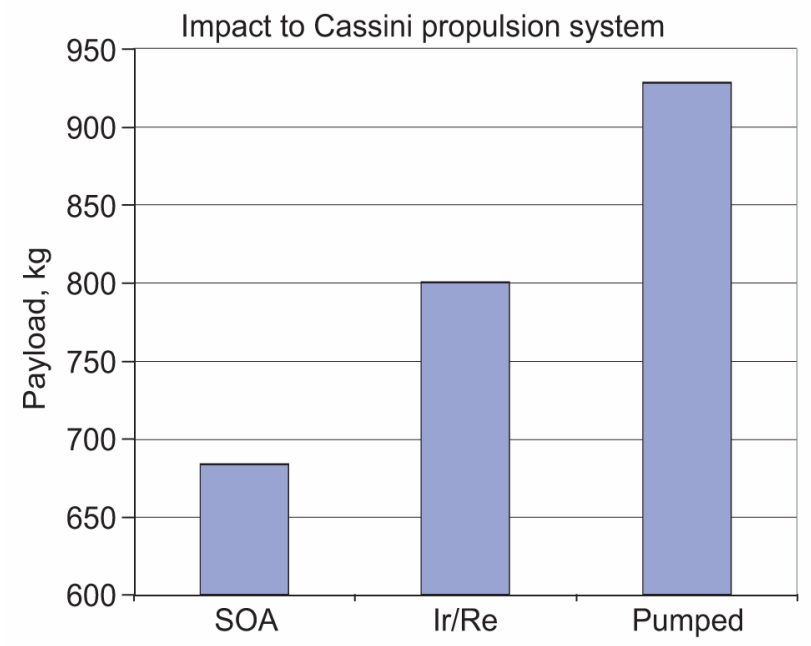

Figure 4.-Payload benefit to CASSINI of pumped system.

\section{One-Dimensional Pump Design}

A mean line pump-flow modeling method (Ref. 11) called PUMPA that was developed at NASA Glenn was used to conduct the conceptual design of the pump. This pump code can model axial, inducer, mixed-flow, and centrifugal pumps and can model multistage pumps in series. It can also be used to model the performance of pumps at off-design operating conditions. The PUMPA flow analysis code was used to explore the design space for this research pump, and for the design of the pump flow path and impeller blades.

This satellite propellant pump development targeted a pressure rise of 500 psia at a flow rate of approximately $1 \mathrm{gpm}$ of hydrazine and nitrogen tetroxide in order to be compatible with $100 \mathrm{lbf}$ class thrusters commonly used on many satellites. Because this research pump was intended to be driven by an electric motor, the design speed was determined in part by the mechanical limitations of the motor to be at a maximum of $60,000 \mathrm{rpm}$. The conceptual design for the satellite pump focused on a four-stage centrifugal pump that could provide the required 500 psia pressure rise with each stage providing a pressure rise of 125 psia (Fig. 5). The four stage pump features a back-to-back configuration to offset axial thrust loads. However, for the purposes of technology demonstration, a two-stage pump tester was designed using water as the surrogate fluid for hydrazine. Sizing the centrifugal pump impeller was done with consideration to keeping the specific speed from being excessively low, in order to maximize pumping efficiency.

Even though there was an effort to keep the specific speed from being too low, the final value of 487 was still low even for a centrifugal. The design rotational speed was 57,000 rpm. The impeller configuration was shrouded, with a smooth seal having 0.003 in. radial clearance to control internal leakages. This tight seal clearance was predicted to provide an impeller with 78 percent efficiency and a stage with 62 percent overall efficiency. The shaft power required to drive the two stage pump was $0.25 \mathrm{hp}$ at the design condition. A two-dimensional centrifugal impeller was designed featuring splitter blades and is shown in Figure 6. The impeller exit diameter was 0.54 in. There was a slight taper through the impeller flow path from the shroud side in order to control the diffusion rate through the blades and limit the relative velocity ratio to a value below 1.9 at the design operating condition. The impeller leading edge metal angle was sized at $18.8^{\circ}$ from the tangential direction, to provide zero incidence with the relative flow angle entering the impeller. The impeller trailing edge was at $36.4^{\circ}$ from the tangential direction to provide the proper amount of pressure rise, and contributes to controlling the diffusion through the blades. The impeller blade featured a simple circular arc shape. The design-point rotor 


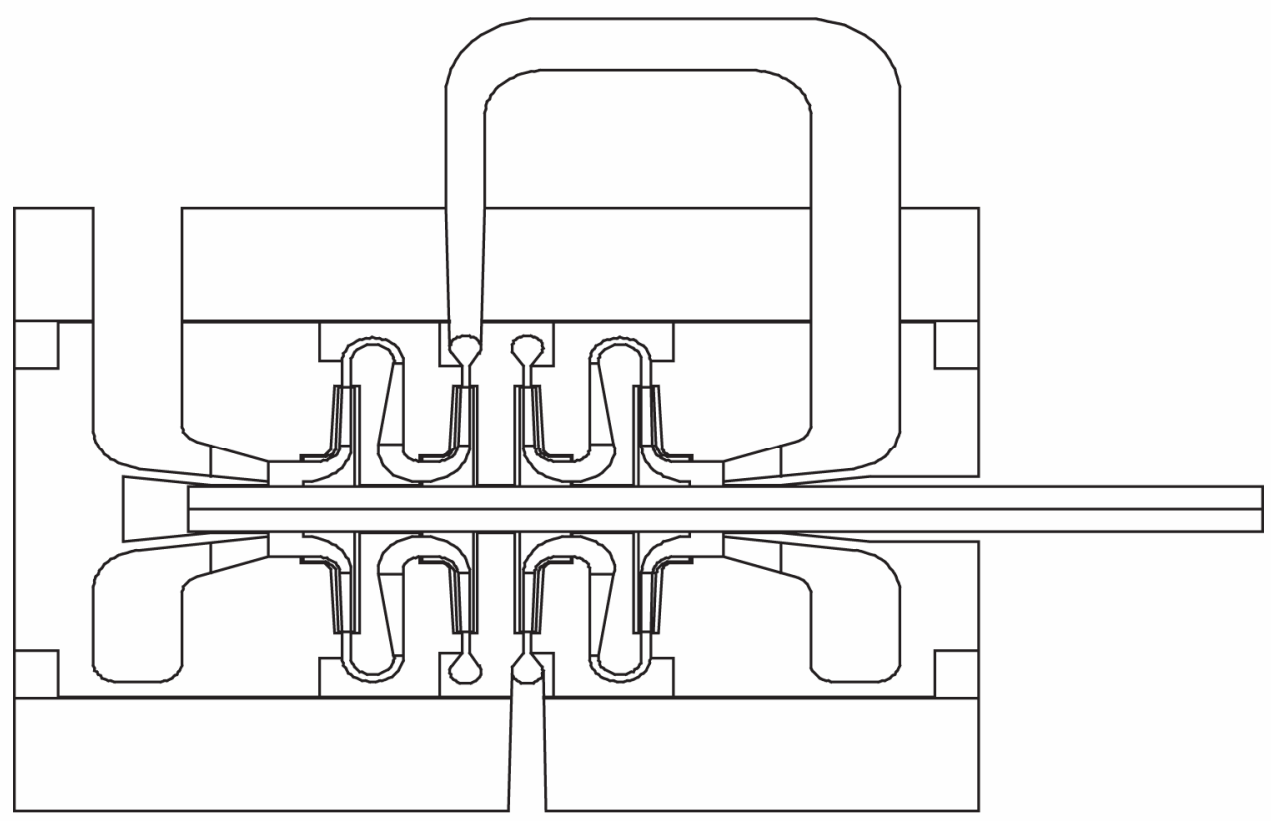

Figure 5.-Conceptual design of four stage satellite pump to meet 500 psia pressure rise.

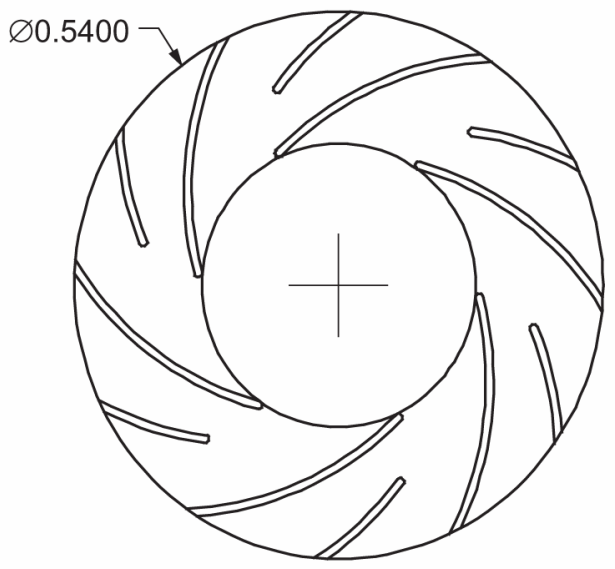

Figure 6.-Centrifugal impeller of 0.54 inch diameter, featuring 6 long blades and 6 splitter, or partial blades.

efficiency and slip factor were modeled in the PUMPA code by empirical correlations to rotor-specific speed and geometry. Based on the slip factor model in the pump code, the calculated value of flow deviation from the impeller exit blade angle was $13^{\circ}$. The second stage impeller blades and flow path were designed to be identical to the first stage.

The diffusion system of the first stage consists of a vaneless radial diffuser, followed by a cross-over diffuser having de-swirl vanes. The cross-over diffuser with radial vanes takes out the swirl from the flow exiting the stage one impeller. This provides an inlet flow into stage two that has zero swirl. The leading edge angle of the cross-over diffuser vanes was sized to provide zero incidence with the incoming flow. The throat area of the de-swirl vanes was sized with the PUMPA flow code model to provide a 0.80 optimal loading parameter (Ref. 11). This resulted in a throat area to diameter ratio (AOD) of 0.007 , 


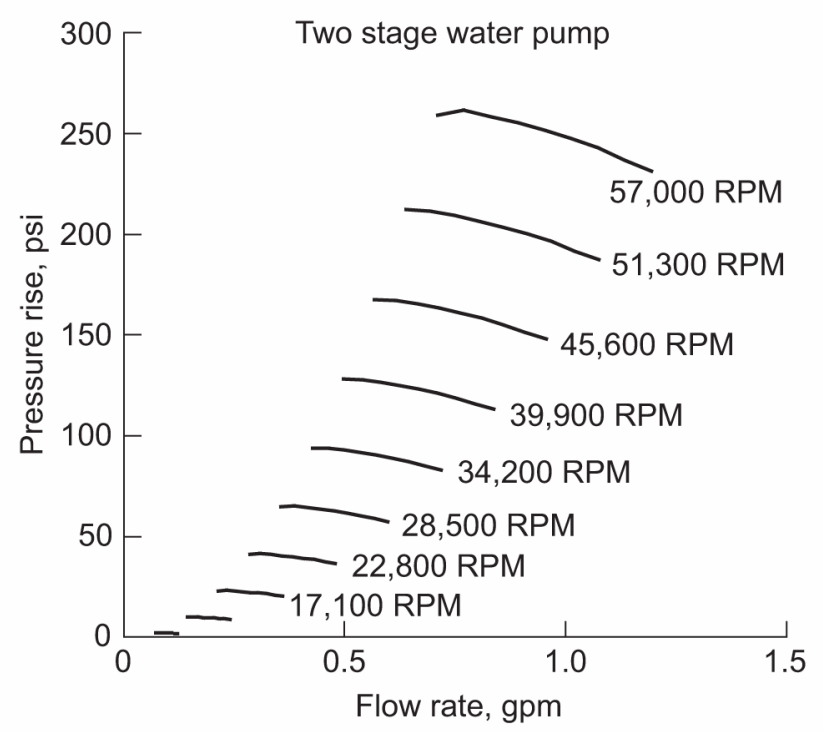

Figure 7.-Two-stage pump performance map.

where the diameter was that of the center of gravity of the throat area. The cross-over diffuser vanes were designed with a gradual, nearly constant change of cross section area through the vane passages from inlet to outlet in order to minimize losses. The diffusion system of the second stage featured a short vaneless diffuser section that was followed by a volute scroll. The volute tongue metal angle was sized to have zero incidence with the flow exiting the second stage impeller, and the volute throat area was also sized for optimal loading parameter using the PUMPA code model.

The performance map for this two-stage pump was modeled with the PUMPA code and is shown in Figure 7, illustrating the pressure rise versus flow rate and speed.

\section{Three-Dimensional Flowfield Analysis}

The flowfield through this pump at the design point was then analyzed with a steady, threedimensional viscous calculation in order to detect any unexpected phenomena such as flow separation. The three-dimensional, unsteady, Navier-Stokes code (HPUMP3D) developed at NASA Glenn and used for various turbomachinery flows (Refs. 12 to 14) was used in the current study. Previous studies have shown that high-order discretization schemes were necessary in both space and time to avoid excessive numerical dissipation. Therefore, a third-order accurate interpolation scheme was used for the spatial discretization of the convection terms and central differencing was used for the diffusion terms. The method yields second-order spatial accuracy on smoothly varying grids.

An implicit, second-order scheme was used for time integration. For unsteady flow calculations, the size of the time step was primarily determined by the requirement for physical accuracy. However, the time step was also restricted by numerical stability. The current implicit time integration approach performed a sub-iteration at each time step to ensure stability and accuracy over a range of physical time steps. The residuals of each finite difference equation were integrated over the entire flow domain at each sub-iteration. When the integrated residuals were reduced by four orders of magnitude from their initial values, the solution was advanced to the next time step. For the current analysis, a computational grid with 40 nodes in the blade to blade direction, 40 nodes in spanwise direction, and 200 nodes from impeller inlet to exit was used.

A modified two-equation turbulence model with near-wall corrections was used to estimate turbulence stresses. At the inlet of the computation domain, the velocity components were specified. At the exit of the computational domain, constant streamwise gradients of the variables were assumed and 


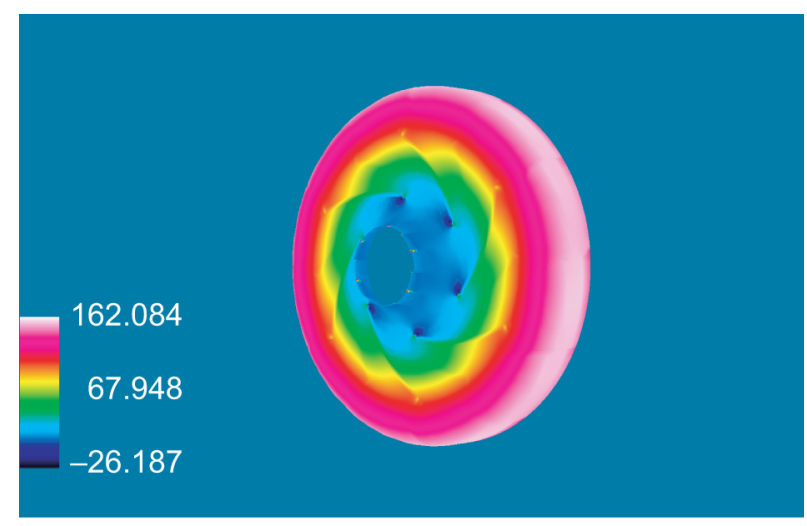

Figure 8.-Calculated static pressure distribution near the shroud of the impeller.

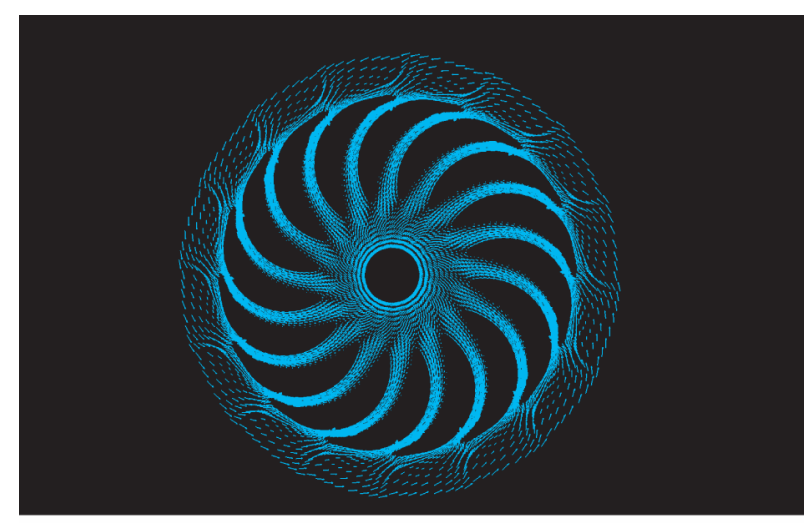

Figure 9.-Calculated velocity vectors near the casing in the de-swirl vane.

total mass conservation was imposed. Figure 8 shows calculated static pressure distribution near the shroud of the impeller with reference to the 50 psia inlet pressure. Calculated velocity vectors near the casing in the de-swirl vane is shown in Figure 9. No flow separation was detected in the analysis and the predicted pressure rise and efficiency were similar to that calculated by the one-dimensional analysis.

\section{Mechanical Design of the Two-Stage Pump}

The two-stage pump mechanical design was conducted by the Engineering Design Division of NASA Glenn. The design was largely driven by the manufacturing processes required to fabricate the precision components. However, the assembly/ disassembly process, the coupling of the motor to the pump, and rotor-dynamics shaped the configuration. Finally, and most importantly, the mechanical design needed to accurately capture the precision aerodynamic pump flow-path required to meet the overall pump performance goals.

A partially assembled pump showing the first stage impeller is shown in Figure 10. A cross section of the pump mechanical design is shown in Figure 11. A high speed electric motor, provided the necessary speed and torque via an integral shaft design. This eliminated any potential shaft coupling/alignment issues associated with separate shafts. The motor's rotor was mounted directly onto the pump shaft, and the stator was incorporated in the motor housing. The motor housing served to house the rear pump bearing and associated pre-load spring, position the motor stator relative to the rotor, and define the 


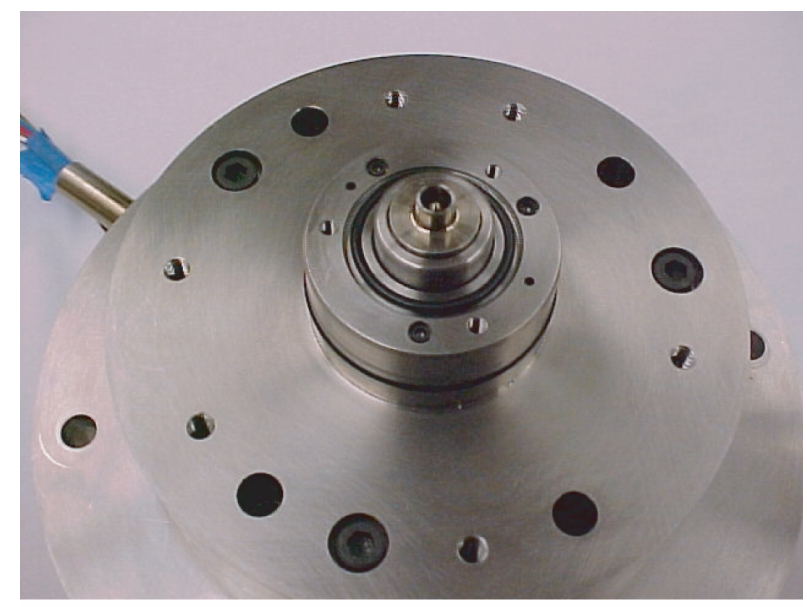

Figure 10.-Partial assembly of pump showing first stage impeller.

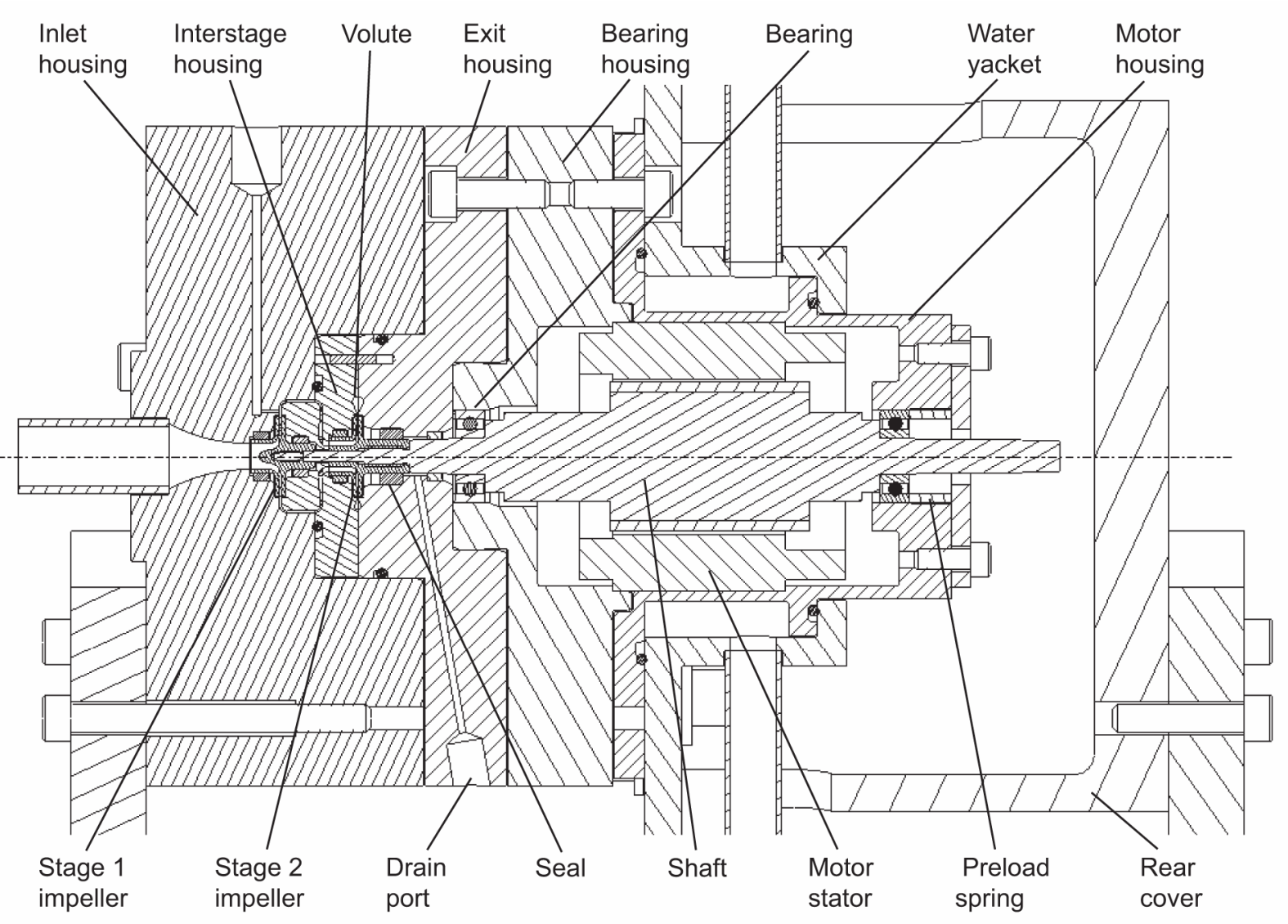

Figure 11.-2-D Pump cross-section. 
flowpath of the motor water cooling jacket. The pump bearings, chosen for the convenience of this test, were commercially available high speed ball bearings with grease packing for lubrication. The bearings were axially preloaded at $3 \mathrm{lb}$ by a wave spring located immediately aft of the rear pump bearing and was axially held in place by the pre-load end cap. The entire motor assembly and cooling jacket was enclosed by the rear cover which also served as a protective shield for all of the rotating motor components. The bearing housing, motor housing cooling jacket and rear cover were all made from 300 series stainless steel.

The impellers (shown in Fig. 12 along with part of the volute) were assembled to the motor shaft as shown in Figure 13 in an overhung manner with the bearing supports on the motor shaft. This design was chosen primarily due to physical space limitations associated with incorporating a relatively large bearing between stage 1 and 2 impellers. Also, the dynamic analysis showed subcritical operation across the entire operating range. A cross section of the turbomachinery assembled to the shaft is shown in Figure 14. The axial location of the impellers was adjusted using a shim near the front bearing. Both impellers were made out of 300 series stainless steel which provided more than sufficient strength and corrosion resistance. In addition, the relative softness of stainless reduced the potential for galling against the harder 17-4 PH shaft material.

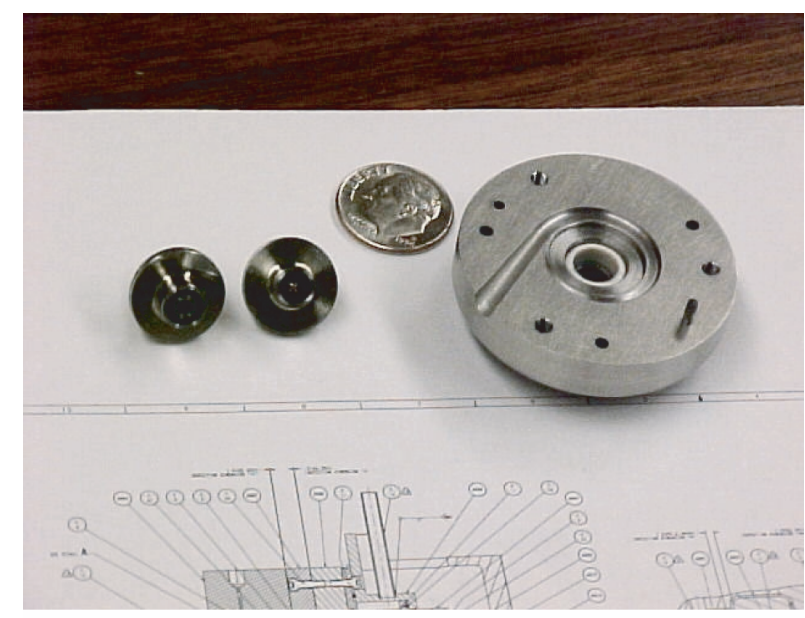

Figure 12.-Impellers and volute.

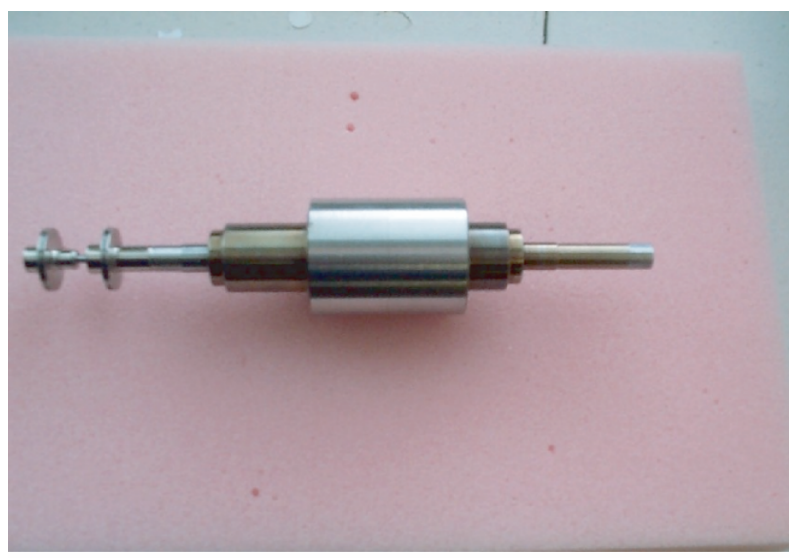

Figure 13.--Impellers assembled on motor shaft. 


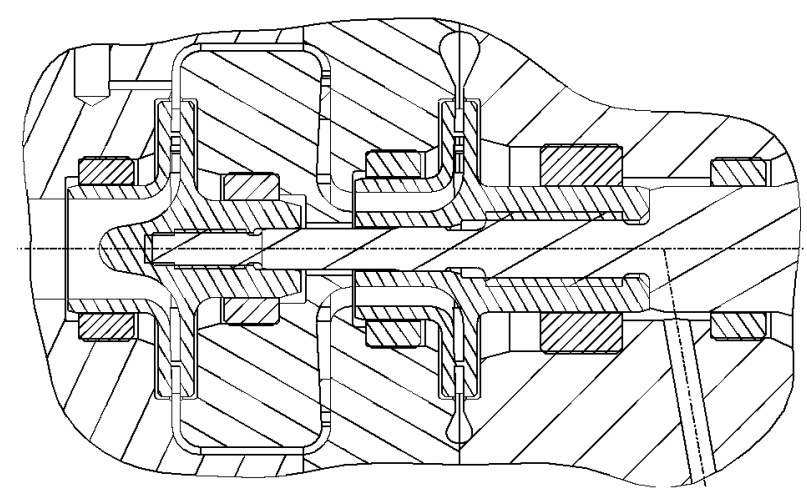

Figure 14.-Cross section of the two-stage pump.

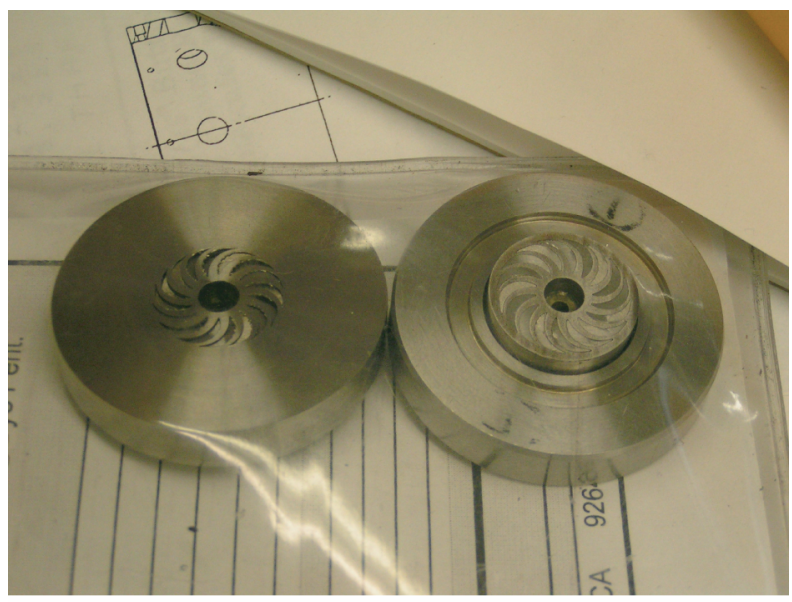

Figure 15._- Interstage housing showing diffuser vanes.

The pump contained five wear ring style seals which can be seen in Figure 14. The physical size of the pump ruled out incorporating commercially available "off the shelf" type seals so custom seals were obtained. Each seal was custom designed to press fit into each of their respective static housings. Once assembled into their housings, the sealing (inside) diameters were then machined to obtain the required clearance. The seals were made out of a high temperature thermoplastic, trade named Permachem 5600, as opposed to a more traditional elastomeric or engineered plastic seal material due to the extremely high pressure and velocity encountered in this application. Permachem 5600 also exhibits excellent wear characteristics and was shown to be compatible with both water as well as the eventual pump working fluid-hydrazine. The sealing surfaces were coated with a nickel plating to obtain the proper hardness.

A seal drain port was integrated into the exit housing in order to drain the seal leakage at the stage 2 aft seal. The exit volute shown in Figure 12 was split axially to enable the assembly and disassembly of the stage 2 impeller as well as to accommodate manufacturing processes required to machine the volute flow path. Due to the low radial loads during operation, only a single volute was required. The inter-stage housing shown in Figure 15 mounted directly to the exit housing and served four primary functions including: (1) half of the volute exit flow path, (2) the ID of the pump cross-over flow path, (3) the pump's diffuser vane housing, and (4) the pump's inter-stage and stage 2 forward seals housing. A pin between the inter-stage and exit housing provided precise radial and circumferential alignment. The pump inlet housing mounted directly to the exit housing and served three primary functions including (1) the housing for the stage 1 seal (2) the OD portion of the pump cross-over flow path and (3) the pump inlet 


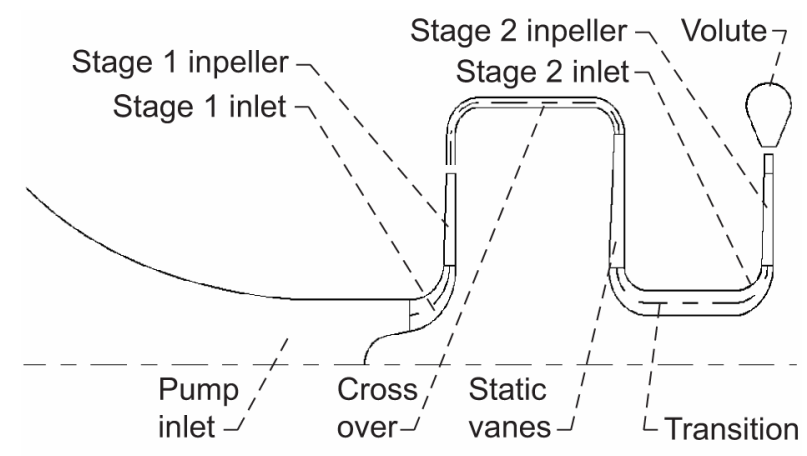

Figure 16.-2-D pump flowpath.

flow path. A static pressure tap was integrated into the inlet housing to measure the static pressure at the exit of the stage 1 impeller. The inlet, interstage and exit housings were all made out of 300 series stainless steel which provided sufficient strength and corrosion resistance. The pump subassembly (inlet, inter-stage, exit and bearing housing) and motor subassembly (motor housing and cooling jacket) were clamped together with bolts, and the entire assembly was mounted to a table through brackets.

The entire flow path of the pump was optimized using various Pro/ENGINEER optimization/ behavioral modeling tools to obtain specific flow parameter values and to obtain smooth flow transitions in order to maximize pump performance. A two-dimensional cross section of the pump flow-path can be seen in Figure 16. The pump inlet incorporated a traditional bell-mouth style pump inlet flow path. The stage 1 impeller inlet flow path was optimized to obtain a smooth, 15 percent linearly decreasing flow area leading to the stage 1 impeller. The sixteen static vanes were designed with an area ratio of $\sim 4.3: 1$, an AOD $\sim 0.007$ and a cone angle (channel diffuser) $\sim 14^{\circ}$. An additional 30 percent area reduction was incorporated between the static vane exit and the stage 2 impeller inlet. The volute was designed with a linearly increasing transition flow area (AR 8.33:1) and an AOD 0.007. In addition, the volute cutwater diameter (diameter at volute tongue) was approximately 10 percent greater than the stage 2 impeller OD in order to control pump noise and efficiency.

\section{Impeller Stress Analysis}

The impellers were analyzed using a combination of hand calculations and finite element analysis software. Given the relative thicknesses of the impeller shrouds and body, and the general robustness of centrifugal hardware designs, the safety margins were high $(>5)$ for both burst speed and bore stress. The total shear stress from both aero and centrifugal loads at the blade/shroud interface where the two pieces are brazed together was only $150 \mathrm{psi}$. The shearing and axial stresses were determined to be acceptable at all shaft locations - the loads included inertial, thrust and acceleration loads.

\section{Dynamics Analysis}

The shaft dynamics shown schematically in Figure 17 were analyzed using a software package called DyRoBeS Rotor, which provided bearing loads, critical speeds, whirl speeds, and time transient response. For this pump application, the limiting dynamic effect was the radial displacements of the impellers. Given the effects of clearance, bearing play, alignment, and tolerance effects, the impellers were dynamically limited to 0.002 in. of radial motion.

A sensitivity study was undertaken to determine the effects of impeller unbalance and damping on the first bending. The effect was dramatic_-increasing unbalance raised the shaft displacement significantly; however, even a small amount of damping and stiffness could reduce the displacement to almost zero. A similar study of the bearing damping showed relatively little affect on the frequency and amplitude. Due to the viscosity of water and the length of the sealing gap, the seals provided a significant amount of 


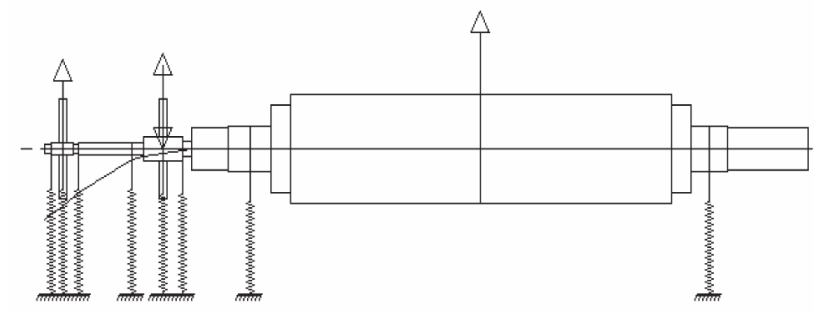

Figure 17.-DyRoBes model.

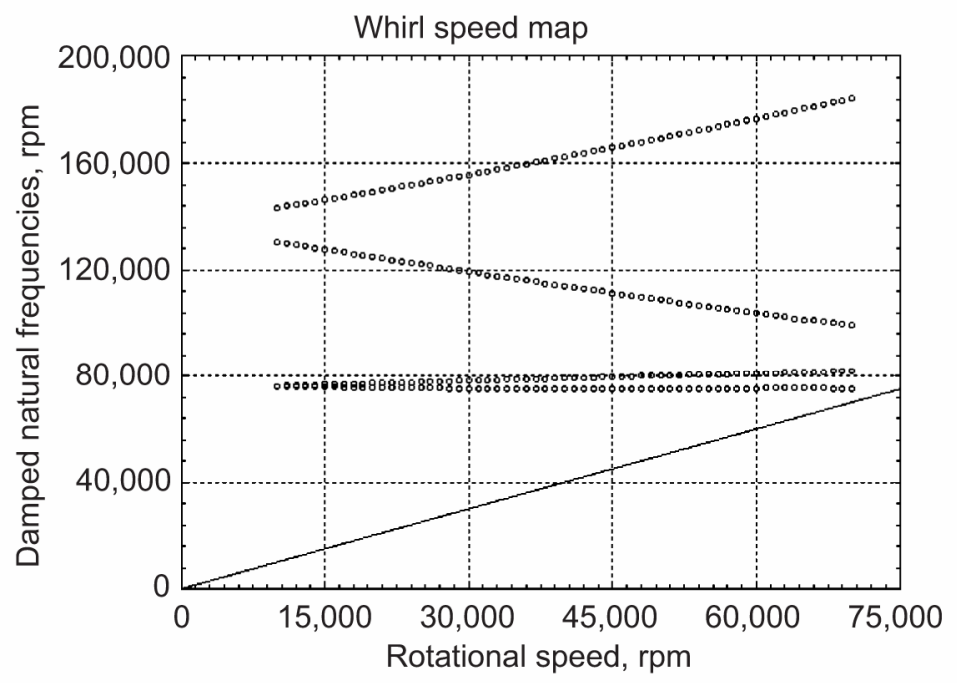

Figure 18.-Pump whirl map.

damping relative the excitement. The damping was determined to be about $0.1 \mathrm{lbf}-\mathrm{s} / \mathrm{in}$ and the stiffness was calculated to be between 286 and $2000 \mathrm{lbf} / \mathrm{in}$. In-house balancing efforts reduced the unbalance to 0.00016 oz.-in. at 3 planes. Figure 18 shows the whirl map with the final inputs shows subcritical operation for both shaft whirl and first critical speed. The largest displacement, at impeller no. 1, is only 0.0007 in. at $57,000 \mathrm{rpm}$.

\section{Facility Description}

A fluid and facility control system was specified and assembled. The drive system consisted of a brushless high speed water-cooled DC motor. The motor was capable of producing $27.2 \mathrm{oz}$.-in. of torque at $60,000 \mathrm{rpm}$. The motor was controlled utilizing a high speed DC motor drive operated via computer.

Data acquisition was accomplished using a data logger communicating via computer with the control program. Motor torque, current draw, input power, and speed were recorded. The data was stored in a spreadsheet for later reduction. Pump instrumentation included static pressures at the pump entrance, the first impeller exit, and at the volute exit along with flow rate and flow temperature. The pressure transducers can be seen in the photograph of the test article in Figure 19. No attempt was made to record high frequency pressure data in these tests. Motor temperature from an imbedded thermocouple was also monitored as a facility diagnostic.

A water cooling jacket was designed to keep the motor stator surface temperature below $150{ }^{\circ} \mathrm{C}$, which was the maximum allowable stator temperature. The water cooling jacket was identified in the drawing in Figure 11. The analysis was based on the conservative assumption that the cooling jacket 


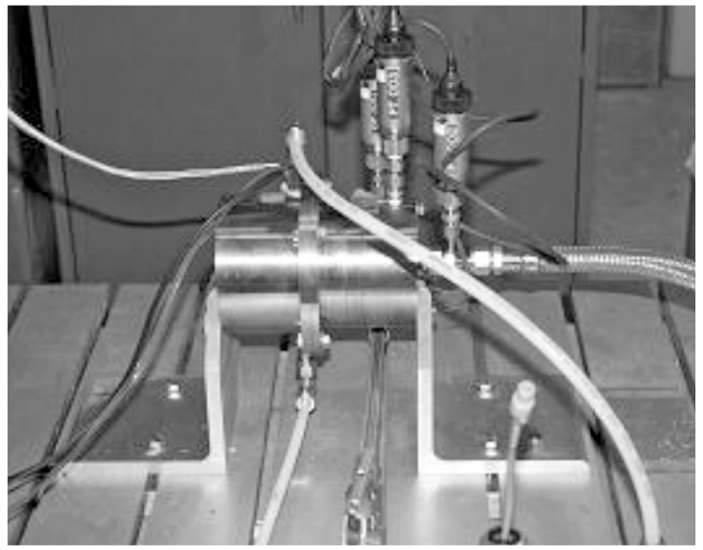

Figure 19.-Photograph of test article.

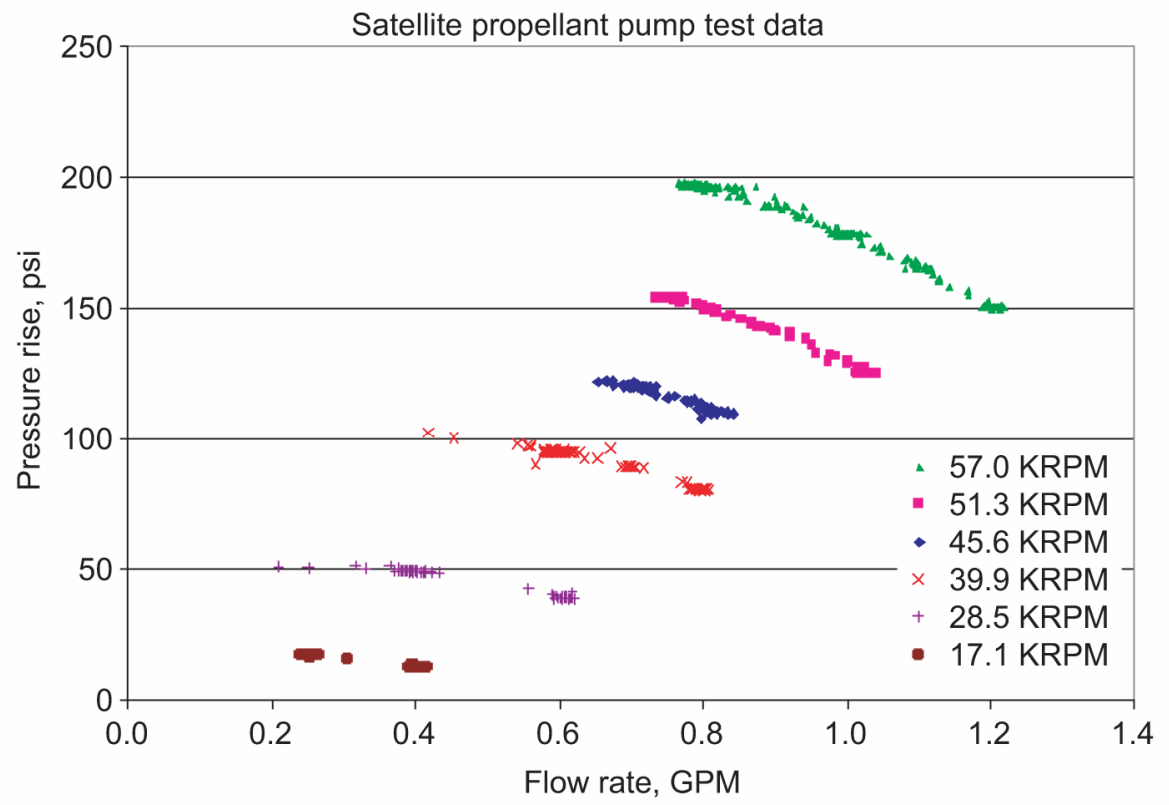

Figure 20.-Two-stage pump test results.

needed to remove all the power losses generated from the motor $(\sim 200 \mathrm{~W})$. The analysis showed the biggest driver of stator temperature to be the size of the air gap between the OD of the stator and the ID of the motor housing. The radial air gap between the stator OD and the motor housing ID was designed to be $\sim 0.0005$ to $0.0015 \mathrm{in}$. Analysis results showed that this size radial air gap would allow the stator surface temperature to be well below the $150{ }^{\circ} \mathrm{C}$ limit. Motor cooling in flight hardware would be accomplished by heat transfer to the propellant flow.

\section{Test Results}

The pump was run at speeds up to 57,000 rpm and flow rates up to $1.2 \mathrm{gpm}$. In general, pressure rises of about 75 percent of the predicted values were observed for the various flow rates and speeds. Speed lines plotted in Figure 20 were selected to match the speed lines plotted in the one-dimensional prediction of Figure 7. For example, a pressure rise of 200 psia was achieved at 57,000 rpm and $0.8 \mathrm{gpm}$ flow rate. This compares with a predicted pressure rise of 260 psia. The predictions were based on empirical data 
from much larger pumps and on the simple blade geometry used on this small impeller. Differences in predicted and actual rotor efficiency and losses in the diffusion system for these small pumps were possible causes of this lower than predicted pressure rise. Based on this data, a pressure rise of 250 psia was predicted at a speed of 64,000 rpm and pump overall efficiency was in the range of 45 to 50 percent. More detailed post test inspection of seal clearances and analysis of the pump and motor performance data will be reported in a subsequent paper.

\section{Conclusion}

A case was made for the incorporation of pumps with a modest pressure rise (500 psia) into satellite propulsion systems. A pumped system was proposed with payload benefits up to 40 percent accruing from both an increase in the rocket performance and a reduction in the pressurization system dry mass. The power requirement $(1 \mathrm{~kW})$ was compatible with a gas generator driven turbine or an electric motor with the power obtained from onboard power storage. A thermodynamic analysis showed the possibility that a gas generator driven turbine could drive the pump and still inject the fuel rich turbine exhaust gas into the rocket combustion chamber eliminating the gas generator penalty. This successful pump design, fabrication and test effort showed that the fabrication technologies exist to build high efficiency satellite propellant pumps with flow rates relevant to satellite propulsion and pressure increases that can significantly benefit mission payloads. The power required to drive the electric pump was consistent with that available on satellites equipped with electric propulsion.

\section{References}

1. Reed, B.D., Biaglow, J.A., and Schneider, S.J., "Iridium-Coated Rhenium Radiation-Cooled Rockets," Proceedings of the International Symposium on Rhenium and Rhenium Alloys sponsored by the Minerals, Metals, and Materials Society, Orlando, FL, February 1997. Also NASA TM-107453, July 1997

2. Jassowski, D.M., "High Pressure Earth Storable Rocket Technology," NASA CR-195427/Vol. 1, October 1997.

3. Chazen, M. and Sicher, D., "High Pressure Earth Storable Rocket Technology Program Summary, AIAA-95-2939, 31 st AIAA/ASME/SAE/ASEE Joint Propulsion Conference, San Diego, July 1995.

4. Siebenhaar, A., "Breadboard Engine Testing of the XLR-132-AJ-1," JANNAF Propulsion Meeting, CPIA Pub. 455, Volume IV, pp. 357-365, August 1986.

5. Wiley, S., Herbert, G., and Mosher, L., "Design and development of the NEAR Propulsion System," AIAA-95-2977, 31st AIAA/ASME/SAE/ASEE Joint Propulsion Conference, San Diego, July 1995.

6. Leeds, M., Eberhardt, R., and Berry, R., "Development of the CASSINI Spacecraft Propulsion Subsystem," AIAA-96-2864, 32 ${ }^{\text {nd }}$ AIAA/ASME/SAE/ASEE Joint Propulsion Conference, Lake Buena Vista, July 1996.

7. Schneider, S.J., "On-Board Propulsion System Analysis of High Density Propellants," AIAA-983670, 34th AIAA/ASME/SAE/ASEE Joint Propulsion Conference, Cleveland, July 1998.

8. Smith, P. and Horton, M., "Advanced Propulsion Systems for Geostationary Spacecraft—Study Results," AIAA-84-1230, 20th AIAA/SAE/ASME Joint Propulsion Conference, Cincinnati, June 1984.

9. Benfield, M. and Belcher, J., "Modeling of Spacecraft Advanced Chemical Propulsion Systems," AIAA-2004-4195, 40th AIAA/ASME/SAE/ASEE Joint Propulsion Conference, Ft. Lauderdale, July 2004.

10. Kawahara, G. And McClesky, S., "Titanium-Lined, Carbon Composite Overwrapped Pressure Vessel," AIAA-96-2751, 32nd AIAA/ASME/SAE/ASEE Joint Propulsion Conference, Lake Buena Vista, July 1996.

11. Veres, J., "Centrifugal and Axial Pump Design and Off-Design Performance Prediction," NASA TM-106745, February 1995. 
12. Hah, C., Puterbaugh, S.L., and Copenhaver, W.W., "Unsteady Aerodynamic Phenomena in a Transonic Compressor Stage," AIAA Paper 93-1868, 1993.

13. Lee, Y., Hah, C., and Loellbach, J., "Unsteady Flow Interaction Inside a High-Reynolds-Number Axial Pump Stage," AIAA Paper 98-0970, 1998.

14. Hah, C., Loellbach, J., Khandelwal, S., and Owen, A.K., "Multidisciplinary Coupling Analysis of Pump Stages for Space Propulsion Systems,” ISABE Paper 2003-1164, 2003. 


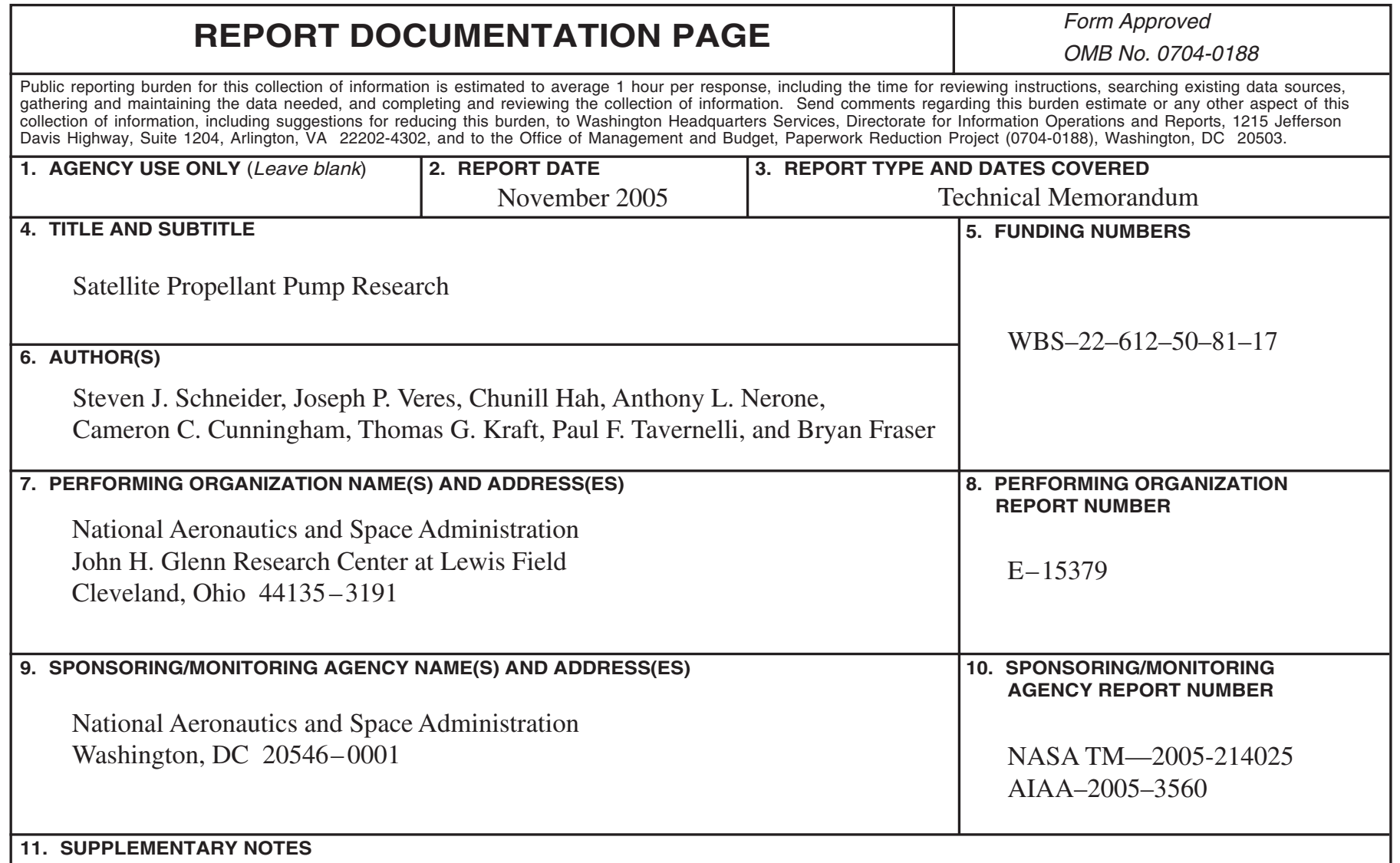

Prepared for the 41st Joint Propulsion Conference and Exhibit cosponsored by AIAA, ASME, SAE, and ASEE, Tucson, Arizona, July 10-13, 2005. Responsible person, Steven J. Schneider, organization code RTS, 216-977-7484.

\begin{tabular}{l|l}
\hline 12a. DISTRIBUTION/AVAILABILITY STATEMENT & 12b. DISTRIBUTION CODE \\
Unclassified - Unlimited & \\
Subject Category: 20 & \\
Available electronically at http://gltrs.grc.nasa.gov & \\
This publication is available from the NASA Center for AeroSpace Information, 301-621-0390. &
\end{tabular}

\section{ABSTRACT (Maximum 200 words)}

NASA Glenn initiated a satellite propellant pump technology demonstration program. The goal was to demonstrate the technologies for a 60 percent efficient pump at $1 \mathrm{gpm}$ flow rate and 500 psia pressure rise. The pump design and analysis used the in-house developed computer codes named PUMPA and HPUMP3D. The requirements lead to a 4-stage impeller type pump design with a tip diameter of 0.54 inches and a rotational speed of 57,000 rpm. Analyses indicated that flow cavitation was not a problem in the design. Since the flow was incompressible, the stages were identical. Only the 2-stage pump was designed, fabricated, assembled, and tested for demonstration. Water was selected as the surrogate fluid for hydrazine in this program. Complete mechanical design including stress and dynamic analyses were conducted. The pump was driven by an electric motor directly coupled to the impellers. Runs up to 57,000 rpm were conducted, where a pressure rise of 200 psia at a flow rate of $0.8 \mathrm{gpm}$ was measured to validate the design effort.

\begin{tabular}{|c|c|c|c|}
\hline \multirow{2}{*}{\multicolumn{3}{|c|}{$\begin{array}{l}\text { 14. SUBJECT TERMS } \\
\text { Centrifugal pumps; Chemical propulsion; Rocket engines; Low thrust propulsion; } \\
\text { Spacecraft propulsion }\end{array}$}} & \multirow{2}{*}{$\begin{array}{l}\text { 15. NUMBER OF PAGES } \\
23 \\
\text { 16. PRICE CODE }\end{array}$} \\
\hline & & & \\
\hline Unclassified & Unclassified & Unclassified & \\
\hline \multicolumn{3}{|l|}{ NSN 7540-01-280-5500 } & $\begin{array}{l}\text { Standard Form } 298 \text { (Rev. 2-89) } \\
\text { rescribed by ANSI Std. Z39-18 } \\
98-102\end{array}$ \\
\hline
\end{tabular}



